\title{
User performance evaluation of the systems for self- monitoring of blood glucose GL50 evo and GL 44 following DIN EN ISO 15197:2015 - A comparison of accuracy in glucose concentration rages $<100 \mathrm{mg} / \mathrm{dl}$ and $\geq 100 \mathrm{mg} / \mathrm{dl}$
}

\author{
Eckhard Salzsieder $^{1 *}$, Puchert $A^{1}$, Ernst-Joachim Freyse ${ }^{1}$ and Berg $\mathbf{S}^{1,2}$ \\ ${ }^{1}$ Institute of Diabetes, Gerhardt Katsch, Karlsburg, Germany \\ ${ }^{2}$ University Medicine Greifswald, Germany
}

Abbreviations: CE: Conformite Europeene; ISO: International Organization for Standardization; SMBG: Self-Monitoring of Blood Glucose.

\section{Introduction}

Ongoing standardized verification of the accuracy of blood glucose meters systems for self-monitoring post-launch is important clinically and helps confirm appropriate continues performance of selfmonitoring blood glucose (SMBG)systems [1]. In addition, publication of such studies is increasingly becoming a component of evidence-based purchase decision making. ISO 15197:2015, [2] for which mandatory compliance is recommended for SMBG systems by 2015, [3] has tighter accuracy requirements than ISO 15197:2003, [4-6] and outlines current minimum accuracy standards necessary in Europe for CE marking.

In the present study, a post-marketing evaluation of the CE-marked GL50 evo and GL44 systems were performed in accordance with ISO 15197:2015 protocols and requirements. The GL50 evo and GL44 systems were supplied in Germany from the Beurer $\mathrm{GmbH}$, Germany. The study was conducted at the Institute of Diabetes "Gerhardt Katsch," Karlsburg, Germany.

Data from $\mathrm{N}=100$ diabetics each ( 55 women and 45 males) were included in the evaluation of this two studies. The knowledge and signing of the consent form were a prerequisite for participation.

The capillary blood glucose values self measured by the volunteers were compared with those obtained by reference methods.

Participants had the following age distribution: The subjects were given the blood glucose meter GL50 evo (first study) or GL 44 (second study) and the instructions for use, created by Beurer Company (Tables 1 and 2). At this time, the patients did not participate in any other study. They got sufficient time to read the instructions and, if necessary, each of them could perform up to three trial runs. Subjects were asked to puncture their fingertips after washing their hands and disinfecting the skin area, and to measure the blood glucose under use of the GL50 evo/ GL 44 blood glucose meter. This action was done under observation by a healthcare professional who took a reference sample from the subject for measurement in the YSI 2300 Stat Plus (YSI Incorporated, USA)

Table 1. Age distribution of subjects

\begin{tabular}{|c|c|c|}
\hline Age (years) & $\begin{array}{c}\text { Number of subjects for } \\
\text { GL50 evo }\end{array}$ & $\begin{array}{c}\text { Number of subjects for } \\
\text { GL44 }\end{array}$ \\
\hline $18-29$ & 9 & 3 \\
\hline $30-39$ & 24 & 12 \\
\hline $40-49$ & 13 & 15 \\
\hline $50-59$ & 23 & 32 \\
\hline $60-69$ & 26 & 27 \\
\hline$>70$ & 5 & 11 \\
\hline Total & 100 & 100 \\
\hline
\end{tabular}

Table 2. Details of educational level

\begin{tabular}{|c|c|c|}
\hline Highest degrees & $\begin{array}{c}\text { Number of subjects for } \\
\text { GL50 evo }\end{array}$ & $\begin{array}{c}\text { Number of subjects for } \\
\text { GL44 }\end{array}$ \\
\hline No degree & 2 & 0 \\
\hline Secondary school & 24 & 17 \\
\hline High school & 3 & 5 \\
\hline Vocational training & 40 & 47 \\
\hline $\begin{array}{c}\text { Technical college, } \\
\text { University }\end{array}$ & 31 & 31 \\
\hline Total & 100 & 100 \\
\hline
\end{tabular}

and an additional blood sample to determine the hematocrit value immediately after patient has done its measurement.

The self-measurement data of the patients and the mesured reference data were coded recorded by the supervisor in the 'User Performance Evaluation Sheets' (=master data sheets) and compiled in the form of an Excel spreadsheet.

Thereafter the user answered to questions from the standardized questionnaire provided to him. Notes and comments from user/subject were noted by the supervisor.

${ }^{\star}$ Correspondence to: Eckhard Salzsieder, Institute of Diabetes, Gerhardt Katsch, Karlsburg, Germany, E-mail: salzsied@diabetes-karlsburg.de

Received: September 27, 2019; Accepted: October 18, 2019; Published: October 21, 2019 
The measured data (blood glucose values and hematocrit) appear in coded form in the files and in the test report.

The analysis of data to verify system accuracy by the user was carried out in accordance with the requirements of DIN EN ISO 15197: 2015. The test measurements were compared with the reference measurements done in the YSI (Tables 3-10).

For samples with glucose concentrations $<100 \mathrm{mg} / \mathrm{dl}$, the deviations from the mean value of the reference samples were calculated in $\mathrm{mg} / \mathrm{dl}$. For samples with glucose concentrations $\geq 100$ $\mathrm{mg} / \mathrm{dl}$, the percentage deviation from the mean of the reference samples was calculated. According to the ISO standard, for glucose concentrations $<100 \mathrm{mg} / \mathrm{dl} 95 \%$ of the measurement results should not deviate more than $\pm 15 \mathrm{mg} / \mathrm{dl}$ from the laboratory reference value and at glucose concentrations $\geq 100 \mathrm{mg} / \mathrm{dl} 95 \%$ of the measurement

Table 3. System accuracy at glucose concentrations $<100 \mathrm{mg} / \mathrm{dL}$

\begin{tabular}{|c|c|c|}
\hline within $\pm \mathbf{5} \mathbf{~ m g / d L}$ & within $\pm \mathbf{1 0} \mathbf{~ m g} / \mathbf{d L}$ & within $\pm \mathbf{1 5} \mathbf{~ m g / d L}$ \\
\hline $7 / 8(87,5 \%)$ & $8 / 8(100 \%)$ & $8 / 8(100 \%)$ \\
\hline
\end{tabular}

Table 4. System accuracy at glucose concentrations $\geq 100 \mathrm{mg} / \mathrm{dL}$

\begin{tabular}{|c|c|c|}
\hline within $\pm \mathbf{5 \%}$ & within $\pm \mathbf{1 0} \%$ & within $\pm \mathbf{1 5 \%}$ \\
\hline $40 / 92(43,5 \%)$ & $66 / 92(71,4 \%)$ & $87 / 92(95 \%)$ \\
\hline
\end{tabular}

Table 5. System accuracy with combined glucose concentrations

\begin{tabular}{|c|c|c|}
\hline within $\pm \mathbf{5} \mathbf{~ m g} / \mathbf{d L}$ & within $\pm \mathbf{1 0} \mathbf{~ m g} / \mathbf{d L}$ & within $\pm \mathbf{1 5} \mathbf{~ m g} / \mathbf{d L}$ \\
$\pm \mathbf{5 \%}$ & $\mathbf{1 0 \%}$ & $\mathbf{1 5 \%}$ \\
\hline $47 / 100(47 \%)$ & $74 / 100(74 \%)$ & $95 / 100(95 \%)$ \\
\hline
\end{tabular}

Table 6. System accuracy at glucose concentrations $<100 \mathrm{mg} / \mathrm{dL}$

\begin{tabular}{|c|c|c|}
\hline within $\pm 5 \mathrm{mg} / \mathrm{dL}$ & within $\pm 10 \mathrm{mg} / \mathrm{dL}$ & within $\pm 15 \mathrm{mg} / \mathrm{dL}$ \\
\hline $7 / 19(36.8 \%)$ & $14 / 19(\mathbf{7 3 . 7 \%})$ & $19 / 19(100 \%)$ \\
\hline
\end{tabular}

Table 7. System accuracy at glucose concentrations $\geq 100 \mathrm{mg} / \mathrm{dL}$

\begin{tabular}{|c|c|c|}
\hline within $\pm \mathbf{5 \%}$ & within $\pm \mathbf{1 0 \%}$ & within $\pm \mathbf{1 5 \%}$ \\
\hline $39 / 81(48.2 \%)$ & $64 / 81(79.0 \%)$ & $76 / 81(94.0 \%)$ \\
\hline
\end{tabular}

Table 8. System accuracy with combined glucose concentrations

\begin{tabular}{|c|c|c|}
\hline $\begin{array}{c}\text { within } \pm \mathbf{5} \mathbf{~ m g} / \mathbf{d L} \\
\mathbf{5} \%\end{array}$ & $\begin{array}{c}\text { within } \pm \mathbf{1 0} \mathbf{~} \mathbf{~ g} / \mathbf{d L} \\
\mathbf{1 0 \%}\end{array}$ & $\begin{array}{c}\text { within } \pm \mathbf{1 5} \mathbf{~ m g} / \mathbf{d L} \\
\pm \mathbf{1 5 \%}\end{array}$ \\
\hline $46 / 100(46 \%)$ & $78 / 100(78 \%)$ & $95 / 100(95 \%)$ \\
\hline
\end{tabular}

Table 9. Answers regarding the operation instructions and device application for GL 50 evo are detailed in the questionnaire

\begin{tabular}{|c|c|c|c|c|c|c|}
\hline & \multirow[b]{2}{*}{$\begin{array}{c}\text { It does } \\
\text { not } \\
\text { apply }\end{array}$} & \multicolumn{3}{|c|}{ Answer } & \multirow[b]{2}{*}{$\begin{array}{l}\text { It does } \\
\text { apply }\end{array}$} & \multirow[b]{2}{*}{$\mathbf{n}$} \\
\hline & & $\begin{array}{l}\text { It does } \\
\text { not } \\
\text { apply in } \\
\text { part }\end{array}$ & Neutral & $\begin{array}{c}\text { It does } \\
\text { apply } \\
\text { in } \\
\text { part }\end{array}$ & & \\
\hline $\begin{array}{l}\text { Instructions for use } \\
\text { understandable }\end{array}$ & 0 & 1 & 8 & 22 & 69 & 100 \\
\hline Instructions easy to follow & 0 & 0 & 8 & 18 & 74 & 100 \\
\hline Easy to install measuring strips & 2 & 2 & 3 & 9 & 84 & 100 \\
\hline $\begin{array}{l}\text { Measurement results clearly } \\
\text { visible }\end{array}$ & 2 & 1 & 0 & 5 & 92 & 100 \\
\hline Blood samples easily taken & 3 & 2 & 4 & 10 & 81 & 100 \\
\hline Error messages understandable & 2 & 0 & 6 & 24 & 68 & 100 \\
\hline Results understandable & 2 & 1 & 3 & 16 & 78 & 100 \\
\hline Meter easy to use & 1 & 4 & 9 & 25 & 61 & 100 \\
\hline Battery replace easy to handle & 3 & 3 & 7 & 14 & 73 & 100 \\
\hline $\begin{array}{l}\text { Error massage explained well } \\
\text { Lancing device was simple } \\
\text { to use }\end{array}$ & $\begin{array}{l}1 \\
4\end{array}$ & $\begin{array}{c}4 \\
11\end{array}$ & $\begin{array}{l}5 \\
6\end{array}$ & $\begin{array}{l}28 \\
17\end{array}$ & $\begin{array}{l}62 \\
62\end{array}$ & 100 \\
\hline
\end{tabular}

Table 10. Answers regarding the operation instructions and device application for GL44 are detailed in the questionnaire

\begin{tabular}{|l|c|c|c|c|c|c|}
\hline & \multicolumn{3}{|c|}{ Answer } & & \\
\hline & $\begin{array}{c}\text { It does } \\
\text { not } \\
\text { apply }\end{array}$ & $\begin{array}{c}\text { It does } \\
\text { not } \\
\text { apply } \\
\text { in part }\end{array}$ & Neutral & $\begin{array}{c}\text { It does } \\
\text { apply } \\
\text { in part }\end{array}$ & $\begin{array}{c}\text { It does } \\
\text { apply }\end{array}$ & n \\
\hline $\begin{array}{l}\text { Instructions for use } \\
\text { understandable }\end{array}$ & 0 & 1 & 4 & 20 & 75 & 100 \\
\hline Instructions easy to follow & 0 & 1 & 1 & 22 & 76 & 100 \\
\hline Easy to install measuring strips & 2 & 2 & 8 & 13 & 75 & 100 \\
\hline $\begin{array}{l}\text { Measurement results clearly } \\
\text { visible }\end{array}$ & 1 & 1 & 1 & 5 & 92 & 100 \\
\hline Blood samples easily taken & 1 & 1 & 0 & 15 & 83 & 100 \\
\hline Error messages understandable & 1 & 0 & 6 & 20 & 73 & 100 \\
\hline Results understandable & 1 & 1 & 1 & 11 & 85 & 99 \\
\hline Meter easy to use & 1 & 0 & 3 & 9 & 86 & 99 \\
\hline Battery replace easy to handle & 1 & 1 & 0 & 17 & 80 & 99 \\
\hline Error massage explained well & 0 & 1 & 1 & 19 & 79 & 100 \\
\hline
\end{tabular}

results should not deviate more than $\pm 15 \%$ from the laboratory reference value. In total, $95 \%$ of the values must meet the defined quality criteria.

\section{Results}

For (blood) samples with glucose concentrations $<100 \mathrm{mg} / \mathrm{dl}$, the deviations from the mean value of the reference samples were calculated and are depicted in $\mathrm{mg} / \mathrm{dl}$. System accuracy of the Beurer GL 44 in the performance evaluation by the user.

Summary performance evaluation by the user: The glucose meters Beurer GL 44 and GL50evo meets the criteria of the EN ISO standard 15197: 2015.

- $95 \%$ of all measured values are within the acceptance limits defined by EN ISO standard 15197: 2015.

- The majority of subjects assessed the use of the manual and of the glucose meter as easy or very easy to understand and/or apply.

\section{Acknowledgment}

Beurer $\mathrm{GmbH}$ were permitted to review and comment on the manuscript, but final decision on content was retained by the authors.

\section{Conflicts of interest}

The author(s) declared the following potential conflicts of interest with respect to the research, authorship, and/or publication of this article: All authors are employees of the Institut fur Diabetes, Karlsburg, Germany, which carries out studies evaluating blood glucose meter systems on behalf of various companies.

\section{Funding}

The author(s) disclosed receipt of the following financial support for the research, authorship, and/or publication of this article: This study was funded by Beurer GmbH Soflinger Str 218, 89077 Ulm Germany.

\section{References}

1. Klonoff DC, Prahalad P (2015) Performance of cleared blood glucose monitors. $J$ Diabetes Sci Technol 9: 895-910.

2. International Organization for Standardization. In vitro diagnostic test systemsrequirements for blood-glucose monitoring systems for self-testing in managing diabetes mellitus. ISO 15197:2013. 
Salzsieder E (2019) User performance evaluation of the systems for self-monitoring of blood glucose GL50 evo and GL 44 following DIN EN ISO $15197: 2015$ - A comparison of accuracy in glucose concentration rages $<100 \mathrm{mg} / \mathrm{dl}$ and $\geq 100 \mathrm{mg} / \mathrm{dl}$

3. Baumstark A, Schmid C, Pleus S, Rittmeyer D, Haug C, et al. (2014) Accuracy assessment of an advanced blood glucose monitoring system for self-testing with three reagent system lots following ISO 15197:2013. J Diabetes Sci Technol 8: 1241-1242.

4. International Organization for Standardization. In vitro diagnostic test systemsrequirements for blood-glucose monitoring systems for self-testing in managing diabetes mellitus. EN ISO 15197:2003.
5. Parkes JL, Slatin SL, Pardo S, Ginsberg BH (2000) A new consensus error grid to evaluate the clinical significance of inaccuracies in the measurement of blood glucose. Diabetes Care 23: 1143-1148.

6. Bland JM, Altman DG (1986) Statistical methods for assessing agreement between two methods of clinical measurement. Lancet 1: 307-310.

Copyright: ( 92019 Salzsieder E. This is an open-access article distributed under the terms of the Creative Commons Attribution License, which permits unrestricted use, distribution, and reproduction in any medium, provided the original author and source are credited. 